\title{
Uncertainty in hydrologic modelling for estimating hydrologic response due to climate change (Santiam River, Oregon)
}

\author{
Christopher G. Surfleet and Desirée Tullos
}

\begin{abstract}
:
This paper explores the predicted hydrologic responses associated with the compounded error of cascading global circulation model (GCM) uncertainty through hydrologic model uncertainty due to climate change. A coupled groundwater and surface water flow model (GSFLOW) was used within the differential evolution adaptive metropolis (DREAM) uncertainty approach and combined with eight GCMs to investigate uncertainties in hydrologic predictions for three subbasins of varying hydrogeology within the Santiam River basin in Oregon, USA. Predictions of future hydrology in the Santiam River include increases in runoff in the fall and winter months and decreases in runoff for the spring and summer months. One-year peak flows were predicted to increase whereas 100-year peak flows were predicted to slightly decrease. The predicted 10-year 7-day low flow decreased in two subbasins with little groundwater influences but increased in another subbasin with substantial groundwater influences. Uncertainty in GCMs represented the majority of uncertainty in the analysis, accounting for an average deviation from the median of $66 \%$. The uncertainty associated with use of GSFLOW produced only an 8\% increase in the overall uncertainty of predicted responses compared to GCM uncertainty. This analysis demonstrates the value and limitations of cascading uncertainty from GCM use through uncertainty in the hydrologic model, offers insight into the interpretation and use of uncertainty estimates in water resources analysis, and illustrates the need for a fully nonstationary approach with respect to calibrating hydrologic models and transferring parameters across basins and time for climate change analyses.
\end{abstract}

\section{INTRODUCTION}

Water resources planning and policy must incorporate changes in hydrology associated with the changing climate (Hamlet et al., 2010). Models indicate that the extent, frequency, and duration of hydrologic extremes, particularly drought or flooding, will be greater in the future than it currently is [Intergovernmental Panel on Climate Change (IPCC), 2007], which can have important consequences for managing water resources. Studies on hydrologic response to climate change in the Pacific north-west (PNW) of the United States indicate that increases in atmospheric air temperature will result in a decreased winter snowpack and increased winter rainfall resulting in earlier flood runoff, lower spring runoff, and lower summer baseflow runoff (e.g. Mote et al., 2003; Tague et al., 2008; Chang and Jung, 2010; Hamlet et al., 2010). These hydrological changes have important implications for water resources management, including maintaining flood risk reduction, meeting irrigation and municipal demands, and supporting the recovery of threatened and endangered species (Mote et al., 2003).

The changing hydrology and failure of stationarity as a fundamental assumption (Milly et al., 2008; Pielke, 2009) provoke questions regarding the validity of current engineering design approaches that are based on probabilities. For example, consider determination of the 100-year peak flow, which is based on historical frequency distributions (e.g. Bedient and Huber, 1992). If the frequency and magnitude of peak flows change in a warming climate, a frequency distribution based on historic conditions would be invalid (Milly et al., 2008). Instead, the use of models for detection of changes in hydrologic conditions may be as important as use of historic conditions. Nonstationary variables that effect hydrologic response (e.g. precipitation, temperature, land use) need to be modelled stochastically to 
describe the temporal evolution of their distributions (Milly et al., 2008). Estimating uncertainty of, and presenting a range of, hydrologic predictions is critical to managing resources under a nonstationary hydrologic regime (Cameron et al., 2000; Maurer, 2007; Milly et al., 2008).

Uncertainties in climate change predictions come from a variety of sources. First, use of global circulation models (GCMs) represents several levels of uncertainty, from lack of knowledge regarding future emissions of greenhouse gases, to differing responses of GCMs to greenhouse gases, to uncertainty added by the downscaling used to translate landscapelevel GCMs to local scales

(Maurer, 2007). Further, land use change is typically not included in GCM simulations representing additional uncertainty (e.g. Mote et al., 2003; Feddema et al., 2005). In addition, the simulation of hydrology presents uncertainties associated with rainfall-runoff models due to both model structure and parameter uncertainties (e.g. Beven and Binley, 1992; Beven, 1993; Brazier et al., 2000).

Typically, uncertainty in GCM use has been investigated by using multiple GCMs with different greenhouse gas scenarios as input to a hydrologic model (e.g. Mote et al., 2003; Maurer and Duffy, 2005; Chang and Jung, 2010). The range of output from the hydrologic model using different GCMs is presented as a demonstration of uncertainty of the future predictions. With few exceptions (e.g. Cameron et al., 2000; Pappenberger et al., 2005), modelling of hydrologic responses due to climate change has generally not attempted to address the propagation of the uncertainties in future climate estimates through uncertainty in the hydrologic model use. Often the mean value from hydrologic predictions is presented without error or confidence limits depicting the uncertainty of the results (e.g. Tague et al., 2008; Hamlet et al., 2010).

Various methodologies have been developed to better address uncertainty in hydrologic modelling. These approaches include state-space filtering, model averaging, and formal and informal Bayesian approaches. Each differs in the underlying assumptions, mathematical rigor, and the way various sources of error are treated (e.g. Beven and Binley, 1992; Beven, 2001; Montanari, 2007; Vrugt et al., 2009a). More formal Bayesian approaches have been developed that attempt to use a true maximum likelihood estimate and consider model errors in their procedure. An example of this approach is the differential evolution adaptive metropolis (DREAM) approach (Vrugt et al., 2009b).

In this study, the DREAM approach was used to cascade uncertainties associated with GCMs through the uncertainty with hydrologic model use. The goal of the work was to investigate uncertainties associated with future hydrologic response to a changing climate. This study's modelling builds on the previous work by Chang and Jung (2010) and Laenen and Risley (1997), who used the precipitation- runoff modelling system [PRMS; a component of the coupled groundwater and surface water flow model (GSFLOW) used in this study] for determining hydrologic response for the Williamette River basin, Oregon, in current and future climate conditions. This work adds the use of a modular groundwater flow model (MODFLOW-2005) for portions of the basin, conducts a formal Bayesian uncertainty assessment of model parameters, and cascades GCM uncertainty through hydrologic model uncertainty. The objectives for this research are to (1) demonstrate the cascading of parameter and forcing data uncertainty from different climate change scenarios through a coupled surface-groundwater model (GSFLOW), (2) evaluate sensitivity of three hydrogeologically distinct regions for hydrologic change and characterize uncertainty of GCM use and hydrologic modelling for the entire Santiam River basin (SRB), and (3) demonstrate the interpretation and benefit of accounting for uncertainty in a climate change assessment. 


\section{METHODS}

\section{Study Area}

The $4700-\mathrm{km}^{2} \mathrm{SRB}$ is a tributary to the Williamette River and is located on the western slopes of the Cascade Range in Oregon, USA (Figure 1). The SRB is divided by the North Fork Santiam River (NF), with a drainage area of $2000 \mathrm{~km}^{2}$, and the South Fork Santiam River (SF), with a drainage area of $2700 \mathrm{~km}^{2}$. The SRB has an elevation range of 50 to 3199 $\mathrm{m}$. The majority of the basin (80\%) is forested mountain terrain, with the remaining $20 \%$ in lower relief foothills, alluvial areas of the Williamette Valley, and some high elevation alpine areas above the tree line. The precipitation averages from $1000 \mathrm{~mm} /$ year to over 2500 $\mathrm{mm}$ /year from the outlet to the highest elevations of the basin (Oregon Climate Service, 2010). The precipitation varies from rain in the Williamette Valley to primarily snow at high elevations, with a mix of rain and snow between. The majority of precipitation occurs from November to May, with little precipitation (on average $<50 \mathrm{~mm}$ ) during summer. Average daily discharge at the outlet of the basin from 1907 to 2010 has been $220 \mathrm{~m}^{3} / \mathrm{s}$, ranging from an average of $40 \mathrm{~m}^{3} / \mathrm{s}$ in summer to $450 \mathrm{~m}^{3} / \mathrm{s}$ in the winter. Runoff from the SRB is regulated by four dams, the Detroit and Big Cliff dams within NF and the Foster and Green Peter dams in SF.

The Cascade Range and SRB are composed primarily of volcanic rocks, consisting of the following: (1) Tertiary basaltic and andesitic rocks together with volcanic debris, primarily in the Western Cascades geology, and (2) Quaternary basaltic and andesitic lava flows, primarily in the High Cascade geology (Baldwin, 1981; Laenen and Risley, 1997) (Figure 1). The Western Cascade geology has moderate to low hydraulic conductivities coupled with shallow soils and abundant clays, forming aquitards and resulting in rapid subsurface flows and little opportunity for groundwater storage (Tague et al., 2008). The High Cascade geology reflects recent constructional volcanism rather than erosional forms. Surface and subsurface hydraulic conductivities in High Cascades are exceptionally high due to highly porous and permeable volcanic layers (Tague and Grant, 2004). The lowlands of the Willamette River valley, at the outlet of the Santiam River, are covered mostly by alluvial coarse-grained deposits that overlay fine-grained deposits (silt to fine sand). Groundwater storage and recharge in these alluvial deposits have a substantial effect on river flows in the Williamette Valley (Lee and Risley, 2002).

\section{GSFLOW Inputs and Set-up}

GSFLOW is a coupled groundwater and surface-water flow model based on the integration of the US Geological Survey (USGS) PRMS (Leavesley et al., 1983) and the USGS MODFLOW (Harbaugh, 2005). GSFLOW allows for three simulation modes: (1) PRMS-only, (2) MODFLOWonly, and (3) integrated GSFLOW (PRMS and MODFLOW combined). For further details on GSFLOW, see Markstrom et al. (2008).

For areas of the Western Cascade geology, PRMS-only simulations were used in the present study due to the lack of a significant groundwater resource. The areas of High Cascade geology and the alluvial deposits of the Santiam River both have substantial groundwater and surface-water interactions, and thus, an integrated GSFLOW modelling approach was used to simulate these areas. The hydrologic response unit (HRU) designations for the subbasins modelled with PRMS-only were based on HRUs previously developed based on similar elevation, soil type, geology, slope and aspect, and land use (Laenen and Risley, 1997; Chang and Jung, 2010). In the areas where an integrated GSFLOW approach was used, the HRUs were developed for spatial continuity such that water movement would route through successive HRUs as it interacted with subsurface groundwater calculations. 
The GSFLOW modelling was parameterized for 16 distinct subbasins within the SRB (Figure 1). Spatial parameters for GSFLOW for all subbasins were created using a 30-m digital elevation model (USGS, 2009), including HRU elevation, HRU area, basin area, HRU aspect, HRU latitude, and HRU longitude. Land cover type, soil types, and geology parameters originated from USGS land cover (2009), NRCS soils (1986), and McFarland's (1983) geology data. There were 13 additional parameter distributions defined from the parameter uncertainty analysis discussed below. Three study subbasins were designated for intensive study for parameter uncertainty analysis with GSFLOW. The three intensive study subbasins were South Fork Santiam River above Cascadia (SFS), Thomas Creek (TCS), and North Fork Santiam River above Boulder Creek (NFS) (Figure 1). Posterior distributions from 13 parameters from the three study subbasins were extrapolated to the remaining subbasins of the SRB based on similarity to historic precipitation type (snow, snow/rain mix, rain), elevation, topography, and groundwater connectivity. The unique characteristics of each of the study subbasins and the subbasins to which study subbasin parameter distributions were transferred are shown (Table I). Default values were used for the remainder of the nonspatial PRMS parameters. Where groundwater modelling was performed, a simple representation of the groundwater interactions was developed using 16$\mathrm{km}^{2}$ grids. The $16-\mathrm{km}^{2}$ finite difference grid was separated into three subsurface layers in subbasins with High Cascade geology and two layers in subbasins with alluvium (Table II).

\section{Historic Climate and Hydrology Data}

GSFLOW was forced by input of daily precipitation, maximum air temperature, and minimum air temperature. The time period used for GSFLOW parameter development and uncertainty analysis for simulation of Santiam River runoff was 1973-2010. The historic daily precipitation and air temperature measurements used for input to GSFLOW came from weather stations in the National Oceanic and Atmospheric Administration's National Weather Service Cooperative Observer Program (NOAA COOP, 2010) and Natural Resource Conservation Service Snow Telemetry sites (NRCS SNOTEL, 2010) (Figure 1). Daily historic streamflow information came from long-term USGS river gauging sites in the basin (USGS NWIS, 2010) (Figure 1). Outflow was available from the Detroit and Foster reservoirs for 1990-2010 (Tom Lowry, Sandia National Lab, unpublished data). The reservoir outflow combined with downstream discharge measurements provided data for the evaluation of fit of modelled runoff below the reservoirs.

\section{Future Climate Information}

To address uncertainty in GCM use, eight GCM simulations with two emission scenarios (B1 and A1B), prepared for the IPCC Fourth Assessment Report (IPCC, 2007) and provided by the Climate Impacts Group (CIG), University of Washington (Table III), were used. GCM simulations were statistically downscaled using the bias correction and spatial downscaling method (Wood et al., 2002; Hamlet et al., 2010) provided by the CIG, University of Washington. The GCM simulations were prepared for the IPCC Fourth Assessment Report (IPCC, 2007). These emission scenarios were most frequently chosen by global modelling groups for future climate change simulations and impact assessment and for mitigation and adaptation options (Chang and Jung, 2010). A statistical downscaling procedure was chosen by the CIG over a dynamic downscaling procedure because of the computational requirements of the models in the dynamic approach (Hamlet et al., 2010). However, dynamic downscaling is an emerging procedure that shows utility for future applications.

The downscaled GCM simulations provided meteorological data, for input to the hydrologic model, on a daily time step at 1/16 degree resolution grid points (Hamlet et al., 2010). For inputs to GSFLOW, which needs to be forced by meteorological data from discreet spatial 
locations, a unit area average of the 1/16 degree meteorological data was developed for each of the 16 subbasins used for the hydrologic modelling in the SRB (Figure 1). The historical time period was modelled using GCM forcing data for the water years 1960-2010, whereas future evaluation periods of 2040 and 2080 were defined by the water years 2030-2059 and 2070-2099, respectively. The change in precipitation and mean daily air temperature from the downscaled GCM data, used as input to the GSFLOW modelling, is presented for the SRB across summer and winter time periods and emission scenario (Figure 2). The range of GCM predicted future precipitation and air temperature generally show greater increases in air temperature during the summer time period and slightly higher precipitation for the winter time period (Figure 2), with the degree of changes higher for the A1B emission scenario.

\section{DREAM Background}

A formal Bayesian approach, DREAM (Vrugt et al., 2009a), was used for determining parameter uncertainty and addressing equifinality in the GSFLOW simulations. The DREAM approach uses a Markov Chain Monte Carlo Sampling algorithm to estimate the posterior probability density function of parameters in complex, high-dimension sampling problems. DREAM runs multiple chains simultaneously for global exploration and automatically tunes the scale and orientation of the a priori distribution during the evolutions to the posterior distribution. The separation of behavioural solutions from nonbehavioural solutions uses a cut-off threshold that is based on the sampled probability mass and, thus, underlying probability distribution (Vrugt et al., 2009b).

The assessment of uncertainty focused on 13 parameters within the PRMS portion of the GSFLOW models. The 13 parameters were parameters of soil and geology hydraulic properties and forcing data corrections (monthly precipitation multipliers and air temperature lapse rates). Ten of the parameters investigated are used in the calculation of soil water transport and exchange of soil water between groundwater and surface runoff. The rain, snow, and air temperature lapse adjustments represented not only parameters in GSFLOW but also corrections to forcing data (downscaled precipitation and air temperatures from GCMs) for the model. The a priori distribution of each parameter was determined from parameter sets developed for the Williamette River basin in previous modelling efforts (Laenen and Risley, 1997; Chang and Jung, 2010) (Table IV).

The DREAM assessment was performed separately for summer and winter time periods for each of three intensive study subbasins (SFS, NFS, and TCS) due to differing hydrologic responses associated with the high and low precipitation periods of the year. The rain and snow adjustment parameters and the maximum and minimum air temperature lapse rates were not evaluated in the summer time periods due to low levels of precipitation and snow melt; values calibrated for the Willamette River basin (Chang and Jung, 2010) were used for summer.

The posterior parameter distributions determined from the DREAM assessment were used to model the runoff for the Santiam River with each downscaled GCM for B1 and A1B scenarios. Following the approach from Pappenberger et al. (2005), forcing data cascaded from eight GCMs with two greenhouse gas emission scenarios was cascaded through 500 behavioural parameter sets produced from the DREAM assessment for summer and winter GSFLOW models. This resulted in 16000 GSFLOW model runs for each subbasin-a total of 224000 model runs across the SRB. The range of output was segregated for each subbasin as the 2.5, 50 (median), and 97.5 percentile values, respectively, calculated from daily streamflow values. 


\section{Application to Ungauged Watersheds}

A common approach, with limitations in nonstationary systems (see Discussion), for modelling ungauged basins is to transfer parameter distributions determined from representative gauged subbasins (e.g. Chang and Jung, 2010; Hamlet et al., 2010) to ungauged basins. To evaluate uncertainty associated with this approach, the parameter sets from SFS and NFS were applied to the Middle Fork Santiam and the Breitenbush River subbasins, respectively, the validation subbasins. These are tributaries in the Santiam River with measured streamflow and are not regulated by reservoirs. The GSFLOW fit for the Middle Santiam and Breitenbush rivers gave an example of the uncertainties in transferring parameter sets from study subbasins to ungauged subbasins.

\section{Hydrologic Response}

Hydrologic response was projected within a framework of uncertainty assessment from the eight GCM projections for the 2040 and 2080 time periods using annual and monthly runoff, 1-year and 100-year peak daily flows, the 10-year 7-day low flow, and the snow water equivalent (SWE) on April 1. The 1-year and 100-year peak daily flows and 10-year 7-day low flow were determined by fitting the annual series of peak daily flows and 7-day lowest flow for each time period to a Log Pearson Type III distribution, respectively. The 1- and 100 -year peak daily flows were chosen to contrast future change in high river flow events that were frequent and extreme, respectively. The 10-year 7-day low flow was selected because it has been used by other researchers in this region (e.g. Hamlet et al., 2010), allowing comparisons. The uncertainties associated with the use of GCM make the use of daily observations questionable (UK Climate Projections, 2012). Although some of the hydrologic response metrics are derived from daily observations, the information is only used in probabilistic distributions to determine changes in trends.

The ensemble mean of the 2.5, median, and 97.5 percentiles of GSFLOW output by scenario, B1 or A1B, was used for interpreting uncertainties in the results. For results of percent change in hydrologic response metrics, the change for the 2.5, median, and 97.5 percentiles was calculated by time period from its historic value. For the peak flow, low flow, and SWE metrics, the high and low values from the range of results are given.

\section{RESULTS}

\section{GSFLOW Fit to Historic Streamflow}

The posterior distributions of parameter sets from the DREAM uncertainty assessment of GSFLOW are given (Table IV). The results of model output fit to the measured streamflow for the three study subbasins of the SRB (Figure 3) show good fit with historic streamflow. The GSFLOW model predicted daily streamflow with Nash Sutcliffe Efficiencies (NSE) and correlation coefficients (r) greater than 0.7 . For monthly streamflow predictions, the NSE and $r$ values are greater than 0.8 and 0.9 , respectively.

The transfer of model parameter sets to the validation basins (Middle Fork Santiam and the Breitenbush River) produced mixed results. The model parameter sets from the SFS transferred well to the Middle Santiam River, with a strong statistical fit for Middle Santiam River to daily streamflow $\left(r=0.77\right.$, NSE $=0.75$, RMSE $\left.=0.12 \mathrm{~m}^{3} / \mathrm{s}\right)$. Statistical fit was not as strong for daily streamflow using the NFS parameters for the Breitenbush River ( $\mathrm{r}=0.77$, NSE $=0.35$, RMSE $=0.79 \mathrm{~m}^{3} / \mathrm{s}$ ). Although similar in some regards (e.g. elevation, vegetation, geology), the extent of High Cascade geology for the Breitenbush River (49\% of catchment area), which affects groundwater storage and discharge, was lower than the NFS ( $90 \%$ of catchment area), resulting in greater uncertainty in the transfer of parameter sets from NFS to the Breitenbush River. This uncertainty is reflected in the range of GSFLOW output around the Breitenbush River streamflow (Figure 3D). The range of 
uncertainty for the GSFLOW predictions of the Breitenbush River is wider than the range shown for the NFS study basins (Figure 3D compared to Figure 3C). Nevertheless, the majority of the Breitenbush River's measured streamflow is within the GSFLOW output confidence intervals (Figure 3D).

\section{Projected changes in runoff and streamflow}

Annual Runoff Changes. The percent change in annual runoff varied by scenario and subbasin (Figure 4); only the NFS and SF are predicted to change, with increases in NFS, a groundwater-dominated basin, and decreases in SF, a mixed surface-water and groundwater basin. The range of annual runoff change for the NF, SFS, and TCS is clustered near zero, with little change predicted for the future (Figure 4). Uncertainty of predicted annual runoff varied by scenario and subbasin; change in the 2.5 and 97.5 percentiles from the range of annual runoff, estimated from the GCM uncertainty cascaded through the hydrologic model uncertainty, spanned a 2-8\% difference from the median percent change.

Monthly Runoff Changes. Generally, future monthly runoff is predicted to increase in the fall and winter months and decrease in the spring and summer months (Figure 5). The future trend becomes more pronounced for the A1B scenario, with higher predicted greenhouse gas emissions, and for the 2080 time period. Given the lack of predicted change in the mean annual runoff for most of the study basins, the increase in runoff volume in fall and winter must be approximately the same as the decrease in spring and summer runoff. The percent change from historical conditions is greater in the late spring and summer months due to relatively larger changes in historic runoff than in fall and winter; however, the volume of runoff is lower in summer and spring.

A range of up to $40 \%$ change was predicted in the TCS subbasin for the summer months for both the B1 and A1B scenarios and in spring and summer months for the A1B scenario (Figure 5C). Generally, the changes in monthly runoff for the 97.5 percentile values reflect a much lower decrease in the summer runoff and a higher increase in winter runoff than the 2.5 and 50 percentile values. The changes in the 2.5, 50, and 97.5 percentile runoff for SFS and NFS were similar throughout the year, with only small deviations for individual months during the winter and spring months. The lower section of TCS is influenced by groundwater from the Williamette Valley, particularly during spring and summer months, which was attempted to be incorporated in the GSFLOW model. However, attempting to represent large aquifer influences within a portion of the TCS subbasin resulted in greater uncertainty during the spring and summer months.

High and low streamflows. Peak daily flows generally are predicted to increase for 1-year events (Figure 6A) and decrease for 100-year events (Figure 6B). However, the highest and lowest predicted 1-year and 100- year values did not always follow the general trend of increased 1-year and decreased 100-year peak flow (Figure 6), illustrating that GCMs predicted a large range for storm events compared to the ensemble mean values. The NFS, with predominantly High Cascade geology and substantial groundwater storage, has the highest variability for both the ensemble mean values and the high and low event predictions.

Predictions of the trend in future 10-year 7-day low flow values for the three study subbasins varied (Figure 7). For both the B1 and A1B scenarios, the median value of the 10year 7-day low flow decreases for 2040 and 2080 in TCS and SFS, basins characterized primarily by surface-water runoff and limited groundwater interactions. Less predicted change and greater uncertainty are predicted for TCS. A slight increase in the 10-year 7-day low flow for 2040 and 2080 is predicted for the NFS, a subbasin with streamflow known to be influenced by groundwater interactions, when compared to historic flows. There is no 
change in the 10-year 7-day low flow for the 2080 time period compared to 2040 for both SFS and NFS. Ensemble mean values of the 2.5, median, and 97.5 percentile values show a slight decrease, although the range of values predicted do not support a conclusive trend.

Snow Water Equivalent (SWE). The mean SWE on April 1 is predicted to decrease from historic values for 2040 and 2080 time periods for the B1 and A1B scenarios (Figure 8). The high elevation subbasin, NFS, is predicted to have 300 to $350 \mathrm{~mm}$ lower SWE on April 1 by 2080. The TCS subbasin is predicted to experience between 2 and $10 \mathrm{~mm}$ decrease in SWE on April 1 by 2080, depending on the greenhouse gas emission scenario, B1 or A1B, respectively. Similarly, predictions for the SFS in the High Cascades indicate potential for a substantial decrease, as much as a 19-mm decrease from historic values of 20-22mm, in SWE on April 1 by 2080, with the largest decrease for the A1B scenario. In the A1B scenario, both the TCS and SFS lowest predicted and median SWE values decrease to near zero by the 2080 time period. However, the highest SWE value do show positive values for SWE in 2080 for TCS and SFS, demonstrating that at least one GCM predicts snow in those basins on April 1 in 2080.

\section{Relative uncertainty in downscaled GCMs and hydrologic model parameter uncertainty}

The contributions of GCMs and hydrologic model parameters to prediction uncertainty are investigated from an ensemble of monthly runoff time series. The relative uncertainty to variability in hydrologic time series is demonstrated with 10 years of monthly runoff predictions for the SFS subbasin. The majority of the runoff prediction range can be attributed to GCM uncertainty, as represented by the median values from the eight GCMs. An average deviation of $66 \%$ from the median of the ensemble of median time series is predicted as the GCM uncertainty. For the GCM uncertainty cascaded through the model parameter uncertainty, an average deviation from the median of $74 \%$ is predicted-an $8 \%$ increase over the GCM uncertainty. This can also be visualized (Figure 9) as the range of monthly runoff from the GCMs and hydrologic model parameter uncertainty against the GCM uncertainty alone. These results confirm the work of others (Maurer and Duffy, 2005; Wilby and Harris, 2006; Buytaert et al., 2009; Ghosh and Mujumdar, 2009; Kay et al., 2009) that have documented greater uncertainty in GCM structure and parameterization than uncertainties associated with hydrologic models.

A plot of 1-year peak daily flows predicted by each of the eight GCMs for the historical time period demonstrates the variations in individual GCM predictions (Figure 10). Several of the 2.5, 50, and 97.5 percentile predictions of 1-year peak daily flows forced by individual GCMs vary from the ensemble mean values. Further, the 1-year daily peak flow varies widely depending on GCM used. This variation in simulated historic flows likely reflects different assumptions made by the different GCMs in predicting climate. However, other factors such as storm inter-arrival times, pre-existing soil moisture conditions, extent of snow pack, and correlations between temperature and precipitation (i.e. warm or cold storms) can cause the flow statistics to diverge from historic.

\section{DISCUSSION}

\section{Hydrologic Response of the SRB to Climate Change with Uncertainty}

Annual and Monthly Changes. The predicted hydrologic responses for SRB of increased fall and winter runoff and decreased spring and summer runoff are consistent with other climate change assessments of hydrology in the PNW (e.g. Mote et al., 2003; Chang and Jung, 2010; Hamlet et al., 2010) and northern climates around the world (e.g. Gellens and Roulin, 1998; Yang et al., 2002; Eckhardt and Ulbrich, 2003). The shift in seasonal runoff has been attributed to warmer air temperatures forcing greater rain precipitation compared to snow 
precipitation. Subsequently less winter snow precipitation results in decreased snow melt runoff in the spring and subsequently lower baseflow in summer (Mote et al., 2003).

The effect of elevation and geology in the mountainous SRB is apparent in the hydrologic predictions. The SFS and TCS mid-elevation study subbasins are projected to experience smaller percent increases in fall and winter precipitation than the high-elevation NFS but much larger percent changes in spring and summer runoff (Figure 5). The NFS is characterized by predominately High Cascade geology and year-round groundwater discharge. The greatest change in April 1 SWE relative to historic conditions (percentage) is predicted for the mid-elevation SFS and TCS study subbasins, particularly in the A1B scenario (Figure 8). Whereas the greatest loss in April 1 SWE is projected for the NFS, the middle elevation subbasins are projected to undergo greater relative change in April 1 SWE. The 2.5 percentile and lowest range values for TCS and SFS are near zero in 2080 for the A1B scenario. The predictions of decreased April 1 SWE suggest an increase in elevation of the transitional rain and snow elevations in the future, as has been documented by other studies (e.g. Elsasser and Bürki, 2002; Scott et al., 2003; Battin et al., 2007). The deep groundwater in the High Cascade geology of the NFS resulted in predictions of future summer low flows at or near historic levels. The mediation of summer low flow changes due to climate change in High Cascade geology are attributed to longer residence times of water stored in deep groundwater aquifers (Tague et al., 2008), creating a lagged yet consistent surface discharge. The SFS and TCS, with predominantly Western Cascade geology, are projected to experience much greater decreases in summer low flow relative to historic conditions, likely due to the rapid response in surface discharge from precipitation inputs in these basins. However, TCS also has alluvial deposits at its lowest elevations that can be associated with groundwater discharge and has the greatest level of uncertainty associated with summer runoff changes (Figure 5C). The presence of a lower percent change in the distribution of summer monthly runoff in TCS could indicate that the groundwater resource mediates some summer low flow changes in subbasins of this type, although the higher uncertainty makes it difficult to draw definitive conclusions on this point.

Peak Flows and Low Flows. Increases in large (>50- to 100-year events) and small peak flows (1-year events) and associated flooding have been predicted in climate change studies for the PNW (e.g. Eckhardt and Ulbrich, 2003; Mote et al., 2003; Hamlet et al., 2010). This study predicted that the 1-year peak daily flow will increase in the future but that the 100year event will decrease in the future, with high uncertainty. The 2.5, 50, and 97.5 percentile 100 -year event predictions trend downward, although the range of predictions has substantial variability. The warmer and wetter winters predicted for the future with more rain than snow will lead to increases in peak flows (Mote et al., 2003) and explain the predicted increase in the 1-year peak daily flow. In contrast, the largest peak flows on record for the SRB have been rain on snow events (for example, the event of record January 1996), where warm air temperatures combined with high amounts of rain precipitation create rapid snow melt and runoff (Marks et al., 1998). In the future, less snow is predicted for the SRB (Figure 8). Decreased winter snow lowers the potential for large rain on snow events, possibly explaining the decrease in the 100-year event. However, the wide range of predicted 100-year events (Figure 6B) reflects considerable variability for future extreme events.

Predictions of the 10-year 7-day low flow indicate that a reduction in low flows will occur in the mid-elevation subbasins with predominately Western Cascades geology that have little deep groundwater inputs. For example, a general decrease is detected in the median 10-year 7-day low flow in the SFS (Figure 7A) and TCS (Figure 7C) study subbasins in the future. The NFS study subbasin, with High Cascade geology and deep groundwater aquifer, is 
projected to undergo a slight increase in the 10-year 7-day low-flow in the future (Figure 7B), though with variability around the results.

\section{Interpretation and Benefits to Uncertainty Assessment}

Modelling Ungauged Basins. Modelling large regional areas requires efficiencies in the development of model parameters where small-scale parameterization is not possible. One approach, used in this study, is to fit the hydrologic model to representative areas then use parameters developed for the representative areas across the larger spatial extent. When evaluating the use of representative GSFLOW parameter sets for modelling ungauged basins, it was found that the strategy worked well in one subbasin but not in another. The median streamflow output of the Breitenbush River did not provide a strong statistical fit (NSE $=0.35$ ) to measured streamflow; the range of streamflow output from the uncertainty assessment is greater (Figure 3D) than the NFS subbasin where the parameters were developed (Figure 3C), although the larger range of uncertainty generally encompassed the measured streamflow values for the Breitenbush River.

The increased uncertainty in the transfer of the parameters from NFS to the Breitenbush River is partially explained by the differing geologies that generate different runoff responses between the basins. Both subbasins had High Cascade geology requiring that a groundwater component be included in the hydrologic modelling. Uncertainty due to the groundwater model parameters was not evaluated due to computing constraints. The importance of the Breitenbush River example is that spatial transfer of parameter sets to similar subbasins will not always generate output with fit similar to the sub basin where the parameters are developed. With the uncertainty quantified, a wider range of runoff predictions was produced for the Breitenbush River, the ungauged subbasin, providing a measure of the level of confidence in the projections that is valuable for planning and decision making.

Interpreting Uncertain Results of Hydrologic Responses. The most common approach to evaluating hydrologic responses to climate change is to ensemble mean values of runoff by future time periods (e.g. Maurer and Duffy, 2005; Maurer, 2007; Hamlet et al., 2010). As an alternative, this study's analysis offers insight into the consistency in predicted change over the entire range of hydrologic responses by estimating ensemble means of the $2.5,50$, and 97.5 percentile values from the cascaded uncertainty. Ensemble means of 2.5, 50, and 97.5 percentiles were used to express different moments around the underlying distribution of output by time period and GCM. Thus, if simulated change is consistent for all percentiles, greater confidence can be placed on conclusions regarding shifts in modelled hydrologic responses. If any of the percentile values provide a result inconsistent with the other percentile values, it notifies the investigator to look for an explanation of the uncertain response.

For example, the ensemble means of monthly runoff for different percentile values by time period reflect relatively consistent trends for the SFS (Figure 5A) and NFS (Figure 5B) subbasins. By predicting similar trends for all percentiles from each of the measures, the conclusions were more robust than simply evaluating one mean value. When the trend for the 2.5, 50, and 97.5 percentile values differ, such as in the TCS subbasin (Figure 5C), a different conclusion can be drawn. The underlying distribution for the TCS subbasin's mean monthly runoff shifted such that the median and smaller percentile values are projected to undergo a substantially lower decrease than values greater than the median during spring and summer runoff (Figure 5C). The higher level of uncertainty could have a physical explanation; TCS has alluvial deposits with groundwater at its lowest elevation that may mediate climate change effects to summer low flows (Tague et al., 2008). Nevertheless the majority of the subbasins did not have a significant groundwater resource. The large range of uncertainty in 
TCS spring and summer streamflow changes, approximately $40 \%$ difference between the 2.5 and 97.5 percentiles, could represent the competing responses of the groundwater resource in the subbasin.

A water resource manager may interpret the TCS results (Figure 5C) as 'within the limits of the uncertainty assessment, a 59\% decrease was most frequently predicted for the July runoff for the 2080 time period. However, the decrease was shown to be as low as $19 \%$ for a substantial number of GCM and model innovations.' Such an interpretation suggests that the frequency of ensemble mean responses carries the highest weight in likelihood of occurrence but that the full range of observations should be considered to indicate a possibility of a different outcome than the most frequent response. Alternately, a manager may choose to emphasize another element of the distribution that is most relevant to their application, such as the maximum change in low flow for the worst-case scenario. Regardless of the element emphasized, it is critical that both the range of responses and their likelihoods be presented to communicate the level of confidence in those responses.

Study Limitations and the Need for a Nonstationary Analytical Framework. In this study, uncertainty is observed in future hydrologic response for two situations. The first is the transfer of parameter sets between two subbasins with deep groundwater influence; NFS's parameters did not provide a good fit when used on the adjacent Breitenbush River. The second situation is the future spring and summer runoff change predicted for the TCS subbasin. In both cases, a groundwater resource is involved in the uncertainty. However, the groundwater itself is not necessarily the reason for uncertainty. Both situations involved subbasins that did not have homogenous hydrologic processes across the entire area. The consideration of the complexity of the hydrologic response of a subbasin will be an important factor in the relative uncertainty of model results.

Relevant to this spatial heterogeneity in the transferring parameters across basins in studies of future climates is recent work that indicates how variation in runoff processes are more strongly driven by climate than by vegetation and soils (Liang and Guo, 2003; Demaria et al., 2007; van Werkhoven et al., 2008; Merz et al., 2011), the factors most commonly used to transfer parameters across basins. Further, Rosero et al. (2010) found that (1) interactions can be more important than the parameters themselves, (2) the interactions between parameters vary across sites, and (3) the parameters that drive model variability, as well as their optimal distributions and their interactions, vary across structurally distinct models (i.e. comparing a model that explicitly includes groundwater against one that represents plant phenology). Given that this study demonstrates climate changes within and across the basins, the strong influence of climate in the transfer of model parameters highlights the fundamental modelling challenges of performing climate change studies in systems characterized by nonstationarity both over time and across the landscape.

Further, it has been found (Wilby, 2005; Vaze et al., 2010) that substantial uncertainties and biases can result from calibration of hydrologic models to historical records, and those biases appear to grow with time since the calibration period (Merz et al., 2011). These results call into question the appropriateness of calibrating hydrologic models by historical streamflow when the relationships between the landscape characteristics and climate are known to change with a changing climate. By assuming that parameters, and their interactions, do not change over time, models, including this study's model, fail to account for possible hydrologic changes (e.g. increases in evapotranspiration, drier soils) that can occur during a warmer climate, potentially resulting in substantial errors for runoff estimations (Merz et al., 2011). Analyses suggest that the bias of calibrating to historical flows may be high for both low flows (Singh et al., 2011) and high flows (Merz et al., 2011). Existing research suggests that the snow-dominated (Singh et al., 2011) and transitional zones (Koster et al., 2004) of 
the SRB may be particularly sensitive to biases associated with calibration to historical observations, as are dry basins (Liang and Guo, 2003; Rosero et al., 2010; Merz et al., 2011; Singh et al., 2011) outside of the study area and areas where future climate deviates strongly from historical temperature and precipitation (Vaze et al., 2010; Singh et al., 2011).

However, the best approach for accounting for temporal instability in model parameters and parameter interactions is not yet apparent (Merz et al., 2011). New approaches for calibrating models for climate change analysis have been proposed, which include, among other recommendations, (i) developing relationships between climate signatures (e.g. runoff ratio) and landscape to substitute space for time (Singh et al., 2011), similar to approaches used in prediction for ungauged basins to managed biases associated with temporal instability, and (ii) calibrating models based on additional hydrologic data (e.g. soil moisture and snow depths) to develop better understanding of temporal variability in parameter interactions and their representation of runoff processes (Merz et al., 2011). Thus, future work is needed to develop truly nonstationary analytical frameworks that include formal assessment of uncertainty evaluation, as presented here, as well as the dynamics in landscape-atmospheric feedback.

\section{CONCLUSIONS}

Evaluation of prediction uncertainty is an essential element of water resources planning that includes climate change. This paper demonstrates how cascading GCM uncertainty through hydrologic model uncertainty can lead to more robust conclusions regarding the types and probabilities of future hydrologic responses. For example, it was found that when transferring hydrologic model parameter sets to ungauged basins, the use of a range of parameter sets, including distinct parameter sets for wet and dry seasons, from the uncertainty assessment assisted in quantifying the uncertainty associated with the transfer. Having this knowledge increases the likelihood of making appropriate interpretations of the predicted response from ungauged basins. Further, the interpretation of uncertainty facilitates the identification of mechanisms for predicted hydrological changes. In this study, a key source of uncertainty appears to be related to differences and variability in hydrogeology, which moderates the influence of groundwater on streamflow, particularly in low flow evaluations. However, a more comprehensive nonstationary framework that addresses the dynamic interactions between a changing climate and the landscape is needed. These interactions have generated concerns both about calibration to historical observations and about the transfer of parameters sets across basins. They lead to the conclusion that a critical area of research in the field of hydrology is the development of a comprehensive analytical framework that includes formal assessment of uncertainty, as demonstrated here, as well as directly addressing the nonstationarity in landscape-climate feedback over space and time.

\section{ACKNOWLEDGEMENTS}

This material is based upon work supported by the National Science Foundation under grant no. 0846360. Any opinions, findings, and conclusions or recommendations expressed in this material are those of the authors and do not necessarily reflect the views of the National Science Foundation. The research was also funded in part by the National Science Foundation through TeraGrid resources provided by Purdue University under grant no. TGECS100006. We specifically acknowledge the assistance of Phil Cheeseman at Purdue University. We thank Heejun Chang and Il-Won Jung of Portland State University for their contributions of climate data, spatial data, and calibrated parameters from their use of PRMS for the Williamette River basin. We received considerable assistance from R. Steven Regan and Rich Niswonger of the United States Geological Survey on the implementation and use 
of GSFLOW. Jasper Vrugt of University of California Irvine provided advice and computer programs for implementation of the DREAM analysis.

\section{REFERENCES}

Baldwin E. 1981. Geology of Oregon. Kendall/Hunt Publishing Co.: Dubuque, Iowa; 170.

Battin J, Wiley M, Ruckelshaus M, Palmer R, Korb E, Bartz K, Imaki H. 2007. Projected changes of climate change on salmon habitat restoration. Proceedings of the National Academy of Sciences 104 (16): 6720-6725. DOI: 10.1073/pnas.07168104

Bedient P, Huber W. 1992. Hydrology and floodplain analysis. Addison-Wesley Publishing Co: Reading, MA; 692.

Beven K. 1993. Prophecy, reality and uncertainty in distributed hydrological modeling. Advance Water Resource 16: 41-51.

Beven K. 2001. Rainfall-Runoff Modeling - The Primer. Wiley: Chichester, UK; 356.

Beven K, Binley A. 1992. The future of distributed models: model calibration and uncertainty prediction. Hydrologic Processes 6: 279-298.

Brazier R, Beven K, Freer J, Rowan J. 2000. Equifinality and uncertainty in physically based soil erosion models: application of the GLUE methodology to WEPP-the Water Erosion Prediction Project-for sites in the UK and USA. Earth Surface Processes and Landforms 25: 825-845.

Buytaert W, Celleri R, Timbe L. 2009. Predicting climate change impacts on water resources in the tropical Andes: Effects of GCM uncertainty. Geophysical Research Letters 36: L07406. DOI:10.1029/2008GL037048

Cameron D, Bevens K, Naden P. 2000. Flood frequency estimation by continuous simulation under climate change (with uncertainty). Hydrology and Earth System Sciences 4(3): 395405.

Chang H, Jung I. 2010. Spatial and temporal changes in runoff caused by climate change in a complex river basin in Oregon. Journal of Hydrology 388: 186-207.

Collins W, Bitz C, Blackmon M, Bonan G, Bretherton C, Carton J, Chang P, Doney S, Hack J, Henderson T, Kiehl J, Large W, McKenna D, Santer B, Smith R. 2006. The community climate system model version 3 (CCSM3). Journal of Climate 19: 2122-2143.

Demaria EM, Nijssen B, Wagener T. 2007. Monte Carlo sensitivity analysis of land surface parameters using the Variable Infiltration Capacity model. Journal of Geophysical Research 112: D11113. DOI:10.1029/2006JD007534

Eckhardt K, Ulbrich U. 2003. Potential impacts of climate change on groundwater recharge and streamflow in a central European low mountain range. Journal of Hydrology 284(1-4): 244-252.

Elsasser H, Bürki R. 2002. Climate change as a threat to tourism in the Alps. Climate Research 20: 253-257.

Feddema J, Oleson K, Bonan G, Mearns L, Buja L, Meehl G, Washington M. 2005. The importance of land-cover change in simulating future climates. Science 310(5754): 16741678. DOI: $10.1126 /$ science. 1118160

Gellens D, Roulin E. 1998. Streamflow response of Belgian catchments to IPCC climate change scenarios. Journal ofHydrology 210(1-4): 242-258.

Ghosh S, Mujumdar PP. 2009. Climate change impact assessment: Uncertainty modeling with imprecise probability. Journal of Geophysical Research 114: D18113.

DOI:10.1029/2008JD011648

Gordon C, Cooper C, Senior C, Banks H, Gregory J, Johns T, Mitchell J, Wood R. 2000. The simulation of SST, sea ice extents and ocean heat transports in a version of the Hadley Centre coupled model without flux adjustments. Climate Dynamics 16: 147-168. 
Hamlet A, Carrasco P, Deems J, Elsner M, Kamstra T, Lee C, Lee S-Y, Mauger G, Salathe E, Tohver I, Whitely Binder L. 2010. Final Project Report for the Columbia Basin Climate Change Scenarios Project. Accessed Sept. 2011:

http://www.hydro.washington.edu/2860/report/

Harbaugh A. 2005. MODFLOW-2005, the U.S. Geological Survey modular ground-water model--the Ground-Water Flow Process. U.S. Geological Survey Techniques and Methods 6A16, variously paginated.

Intergovernmental Panel on Climate Change (IPCC). 2007. Climate Change 2007: The Scientific Basis. IPCC Contribution of Working Group I to the Fourth Assessment Report of the Intergovernmental Panel on Climate Change. Cambridge University Press, Cambridge. Available online and accessed Sept. 2011:

http://www.ipcc.ch/publications_and_data/publications_and_data_reports.shtml

Pielke Jr, R. 2009. Collateral damage from the death of Stationarity. GEWEX - Global Energy and Water Cycle Experiment 5-7, May 2009.

Jungclaus J, Botzet M, Haak H, Keenlyside N, Luo J, Latif M, Marotzke J, Mikolajewicz U, Roeckner E 2006. Ocean circulation and tropical variability in the coupled model ECHAM5/MPI-OM. Journal of Climate 19: 3952-3972.

K-1 model developers. 2004. K-1 coupled model (MIROC) descrption. In K-1 technical report 1: Center for Climate System Research, Hasumi H, Emori S (eds). University of Tokyo: Tokyo, Japan; 34.

Kay AL, Davies HN, Bell VA, Jones RG. 2009. Comparison of uncertainty sources for climate change impacts: Flood frequency in England. Climatic Change 92: 41-63.

Koster RD, Dirmeyer PA, Guo ZC, Bonan G, Chan E, Cox P, Gordon CT, Kanae S, Kowalczyk E, Lawrence D, Liu P, Luo CH, Malyshev S, McAvaney B, Mitchell K, Mocko D, Oki T, Oleson K, Pitman A, Sud YC, Taylor CM, Verseghy D, Vasic R, Xue YK, Yamada T. 2004. Regions of strong coupling between soil moisture and precipitation. Science 305(5687): 1138. DOI:10.1126/ science.1100217

Laenen A, Risley J. 1997. Precipitation-runoff and streamflow-routing models for the Williamette River basin, Oregon. USGS Water Res. Investigation Rep. 95-4284. 197.

Leavesley G, Lichty R, Troutman B, Saindon L. 1983. Precipitation-runoff modeling systemuser's manual. U.S. Geological Survey Water-Resources Investigations Report 83-4238, 207.

Lee K, Risley J. 2002. Estimates of ground-water recharge, base flow and stream reach gains and losses in the Williamette River basin, Oregon. U.S. Geological Survey Water-Resources Investigations Report 01-4215, 53.

Liang X, Guo J. 2003. Intercomparison of land surface parameterization schemes: Sensitivity of surface energy and water fluxes to model parameters. Journal of Hydrology 279: 182-209. DOI:10.1016/S0022- 1694(03)00168-9

Marks D, Kimball K, Tingey D, Link T. 1998. The sensitivity of snowmelt processes to climate conditions and forest cover during rain-on-snow: a case study of the 1996 Pacific Northwest flood. Hydrological Processes 12: 1569-1587.

Markstrom S, Niswonger R, Regan R, Prudic D, Barlow P. 2008. GSFLOW--Coupled Groundwater and Surface-water FLOW model based on the integration of the Precipitation-Runoff Modeling System (PRMS) and the Modular Ground-Water Flow Model (MODFLOW2005). U.S. Geological Survey Techniques and Methods 6-D1, 240.

Marti O, Bracommot P, Bellier J, Benshila R, Bony S, Brockmann P, Cadulle P, Caubel A, Denvil S, Dufresne J, Fairhead L, Filiberti M, Hourdin F, Krinner G, Levy C, Musat I, Talandier C. 2005. The new IPSL climate system model: IPSL-CM4. Institut Poerre Simon Laplace des Sciences de l'Environnement Global. Accessed Sept. 2010: http:// dods.ipsl.jussieu.fr/omamce/IPSLCM4/ 
Maurer E. 2007. Uncertainty in hydrologic impacts of climate change in the Sierra Nevada, California, under two emissions scenarios. Climatic Change 82: 309-325.

Maurer E, Duffy P. 2005. Uncertainty in projections of streamflow changes due to climate change in California. Geophysical Research Letters 32. DOI 10.1029/2004GL021462

McFarland W. 1983. A description of aquifer units in Western Oregon. US Geological Survey Open-File Report 82-165, 35.

Merz R, Parajka J, Blöschl G. 2011. Time stability of catchment model parameters: Implications for climate impact analyses. Water Resources Research 47: W02531. DOI:10.1029/2010WR009505

Milly PCD, Betancourt J, Falkenmark M. 2008. Climate Change: Stationarity Is Dead: Whither Water Management? Science 319 (5863): 573-574.

Min S, Legutke S, Hense A, Kwon W. 2005. Internal variability in a 1000 year control simulation with the coupled climate model ECHO-G. Part I. Near-surface temperature, precipitation and sea level pressure. Tellus 57A: 605-621.

Montanari A. 2007. What do we mean by uncertainty? The need for a consistent wording about uncertainty assessment in hydrology. Hydrologic Processes 21(6): 841-845.

DOI:10.1002/hyp.6623

Mote P, Parson E, Hamlet A, Ideker K, Keeton W, Lettenmaier D, Mantua N, Miles E, Peterson D, Peterson D, Slaughter R, Snover A. 2003. Preparing for climate change: the water, salmon, and forests of the Pacific Northwest. Climatic Change 61: 45-88.

National Oceanic and Atmospheric Administration Cooperative Observer Program (NOAA COOP). 2010. Daily precipitation and maximum \& minimum temperature data. Accessed from the Internet July 1, 2010: http://www.nws.noaa.gov/om/coop

Natural Resources Conversation Service (NRCS). 1986. General soil map, state of Oregon. Portland, Oregon, Natural Resource Conservation Service, scale 1:1000,000.

Natural Resources Conversation Service Snow Telemetry System (NRCS SNOTEL). 2010. Accessed from the Internet July 1, 2010: http://www.

or.nrcs.usda.gov/snow/maps/oregon_sitemap.html

Oregon Climate Service. 2010. PRISM map of annual precipitation of the United States. downloaded from the Internet on July 28, 2010 at: http://www.ocs.oregonstate.edu/index.html

Pappenberger F, Beven K, Hunter N, Bates P, Gouweleeuw B, Thielen J, de Roo APJ. 2005. Cascading model uncertainty from medium range weather forecasts (10 days) through a rainfall-runoff model to flood inundation predictions within the European Flood Forecasting System (EFFS). Hydrology and Earth System Sciences 9(4): 381-393.

Rosero E, Yang ZL, Wagener T, Gulden LE, Yatheendradas S, Niu GY. 2010. Quantifying parameter sensitivity, interaction, and transferability in hydrologically enhanced versions of the Noah land surface model over transition zones during the warm season. Journal of Geophysical Research 115: D03106. DOI:10.1029/2009JD012035

Scott D, McBoyle G, Mills B. 2003. Climate change and the skiing industry in southern Ontario (Canada): exploring the importance of snowmaking as a technical adaptation. Climate Research 23: 171-181.

Singh R, Wagener T, van Werkhoven K, Mann M, Crane R. 2011. A trading-space-for-time approach to probabilistic continuous streamflow predications in a change climate - accounting for changing watershed behavior. Hydrology and Earth System Sciences 15: 3591-3603. DOI: 10.5194/hess-15-3591-2011

Tague C, Grant G. 2004. A geologic framework for interpreting the low-flow regimes of Cascade streams, Williamette River Basin, Oregon. Water Resources Research 40: W04303. DOI: 10.1029/2003WR002629, 9 p 
Tague C, Grant G, Farrell M, Choate J, Jefferson A. 2008. Deep groundwater mediates streamflow response to climate warming in the Oregon Cascades. Climatic Change 86: 189210. DOI: $10.1007 /$ s10584-007-9294-8

Terray L, Valcke S, Piacentini A. 1998. Oasis 2.2 Ocean Atmosphere Sea Ice Soil. User's Guide and Reference Manual, Technical Report TR/ CMGC/98-05, CERFACS, Toulouse, France.

UK Climate Projections. 2012. Climate change projections what to be aware of. Accessed Internet June 29, 2012: http://ukclimateprojections. defra.gov.uk/22552

US Geological Survey (USGS) Seamless. 2009. National Map Seamless Server. Accessed Internet Dec. 10, 2009: http://seamless.usgs.gov/index.php

US Geological Survey National Water Information System (USGS NWIS). 2010. USGS Surface-Water Data for the Nation. Accessed Internet July 1, 2010: http://waterdata.usgs.gov/nwis/sw

Vaze J, Post D, Chiew F, Perraud J-M, Viney N, Teng J. 2010. Climate non-stationarity Validity of calibrated rainfall-runoff models for use in climate change studies. Journal of Hydrology 394(3-4): 447-457. DOI:10.1016/j.jhydrol.2010.09.018

Vrugt J, ter Braak C, Diks C, Gupta H, Robinson B. 2009a. Equilifinality of formal (DREAM) and informal (GLUE) Bayesian approaches in hydrologic modeling? Stochastic Environmental Research and Risk Assessment 23: 10111026.

Vrugt J, ter Braak C, Diks C, Higdon D, Robinson B, Hyman J. 2009b. Accelerating Markov chain Monte Carlo simulation by differential evolution with self-adaptive randomized subspace sampling, International Journal of Nonlinear Sciences and Numerical Simulation 10(3): 273-290. Washington W, Weatherly J, Meehl G, Semtner A, Bettge T, Craig A, Strand W, Arblaster J, Wayland V, James R, Zhang Y. 2000. Parallel climate model (PCM) control and transient simulations. Climate Dynamics 16: 755-774.

van Werkhoven K, Wagener T, Reed P, Tang Y. 2008. Characterization of watershed model behavior across a hydroclimatic gradient. Water Resources Research 44: W01429. DOI:10.1029/2007WR006271

Wilby RL. 2005. Uncertainty in water resource model parameters used for climate change impact assessment. Hydrological Processes 19: 3201-32219. DOI:10.1002/hyp.5819

Wilby RL, Harris I. 2006. A framework for assessing uncertainties in climate change impacts: Low-flow scenarios for the River Thames. UK. Water Resources Research. 42: W02419. DOI:10.1029/ 2005WR004065

Wood A, Maurer E, Kumar A, Lettenmaier D. 2002. Long-range experimental hydrologic forecasting for the eastern United States. Journal of Geophysical Research-Atmospheres 107: 4429-4443.

Yang D, Kane DL, Hinzman LD, Zhang X, Zhang T, Ye H. 2002. Siberian Lena River hydrologic regime and recent change. Journal of Geophysical Research 107(D23): 4694. DOI:10.1029/ 2002JD002542.10p 


\section{Figures and Tables}

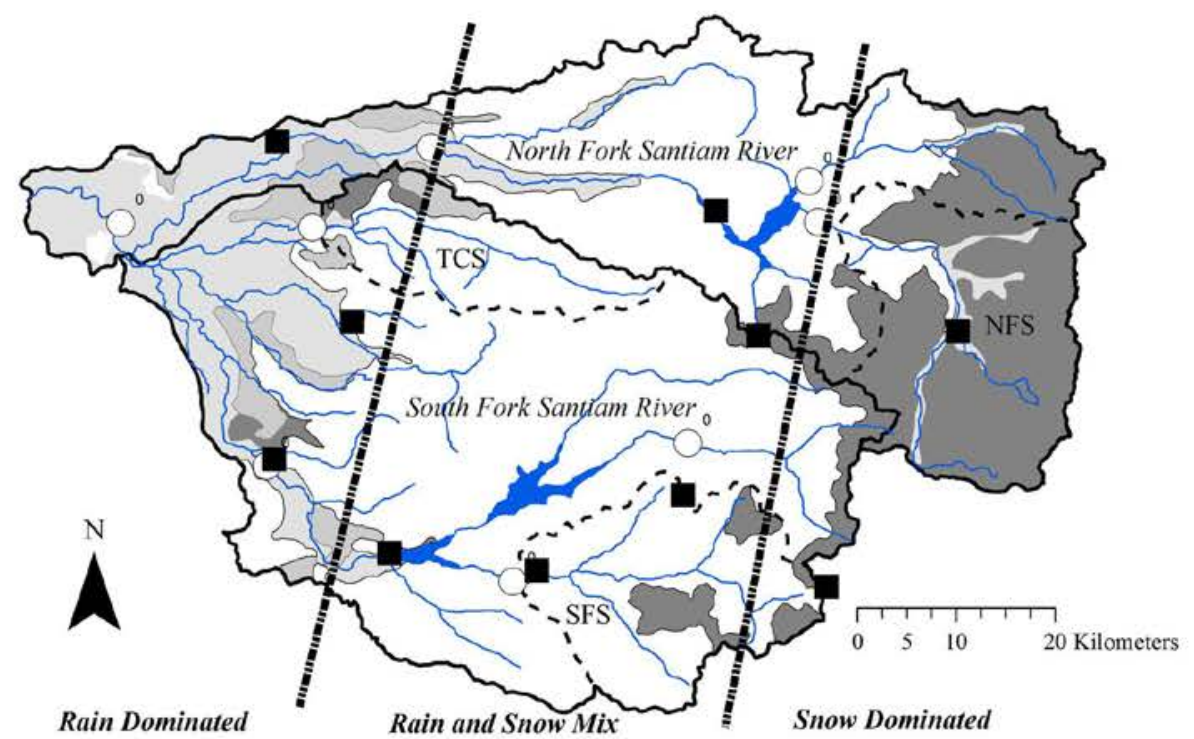

\section{Legend}

Weather Stations

Santiam River Gauges Reservoirs

I. Study Sub-basins Geology

Alluvium

Columbia River Basalts

High Casacades Geology

$\square$ Western Cascades Geology
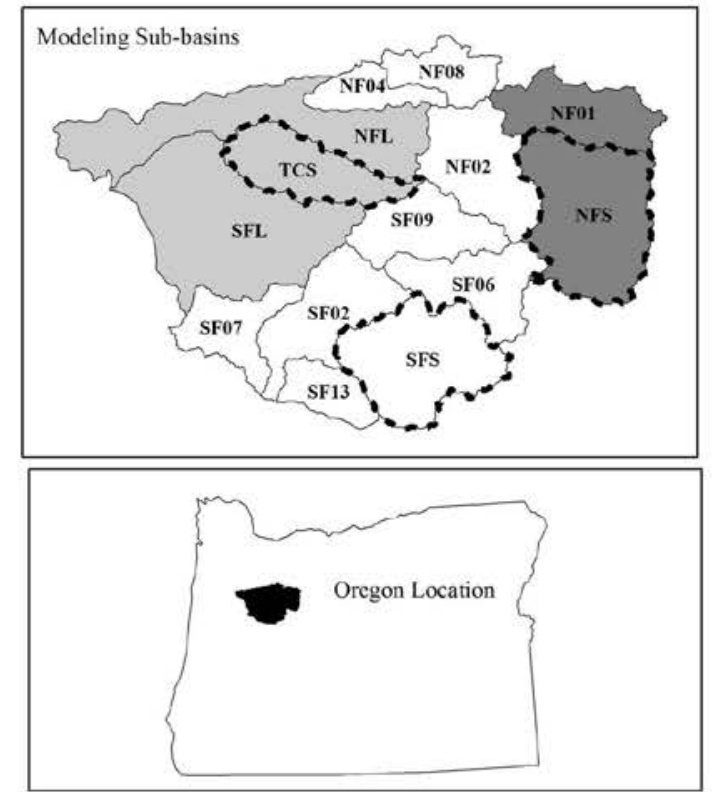

Figure 1. Santiam River basin (SRB) geology, historic weather stations, river gauges, dominant precipitation, and study subbasins. Top inset: modelling subbasins with extrapolation of uncertainty assessment parameter distributions by colour. Bottom inset: location of basin in Oregon, USA 


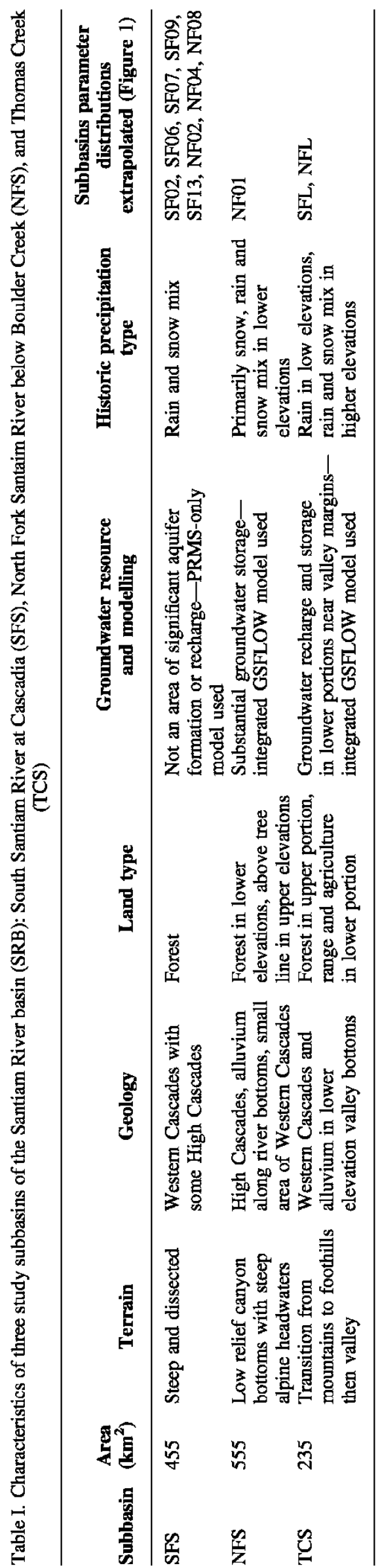




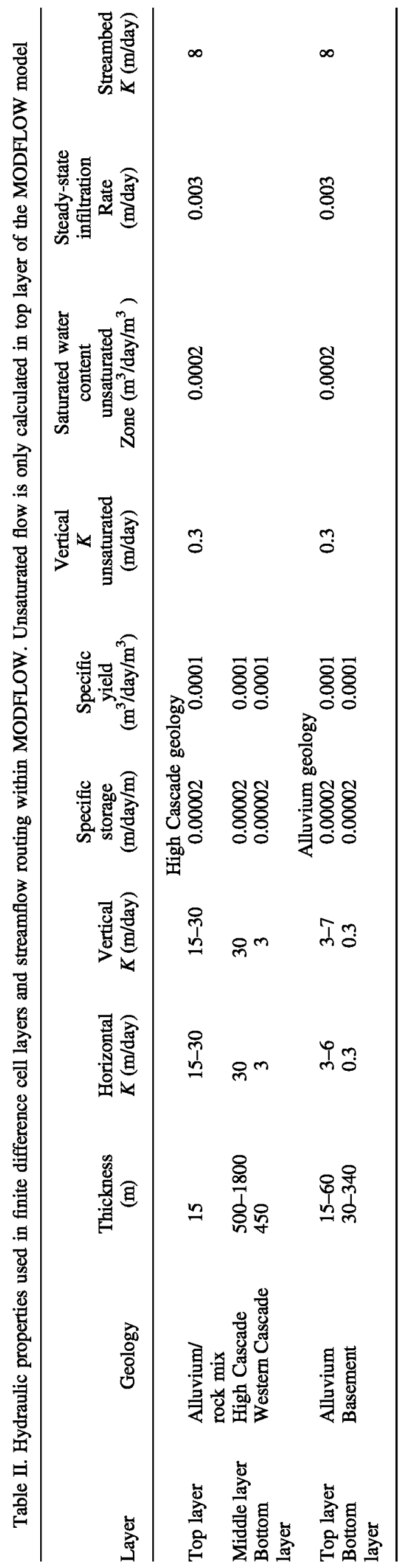


Table III. Description of eight global circulation models (GCM) used in this study

\begin{tabular}{|c|c|c|}
\hline GCM & $\begin{array}{c}\text { Country of } \\
\text { origin }\end{array}$ & References \\
\hline CCSM3 & United States & Collins et al. (2006) \\
\hline CNRM-CM3 & France & Terray et al. (1998) \\
\hline ECHAM5/MPI-OM & Germany & Jungclaus et al. (2006) \\
\hline ECHO-5 & Germany/Korea & Min et al. (2005) \\
\hline IPSL-CM4 & France & Marti et al. (2005) \\
\hline MIROC3.2 & Japan & K-1 Developers (2004) \\
\hline PCM & United States & Washington et al. (2000) \\
\hline UKMO-HadCM3 & United Kingdon & Gordon et al. (2000) \\
\hline
\end{tabular}
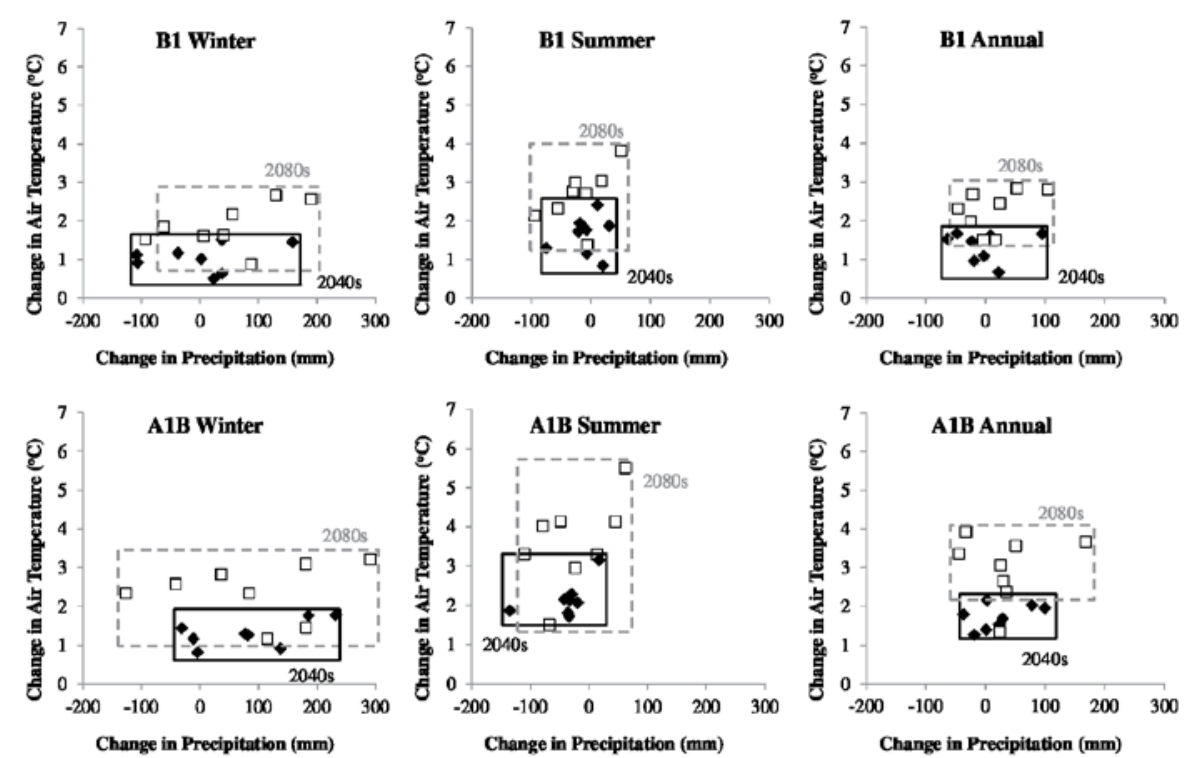

Figure 2. Average change in air temperature and precipitation for B1 and A1B emission scenarios for eight GCM predicting the 2040 and 2080 time periods for the Santiam River basin (SRB). For this study, winter months are November through April; summer months are May through October 


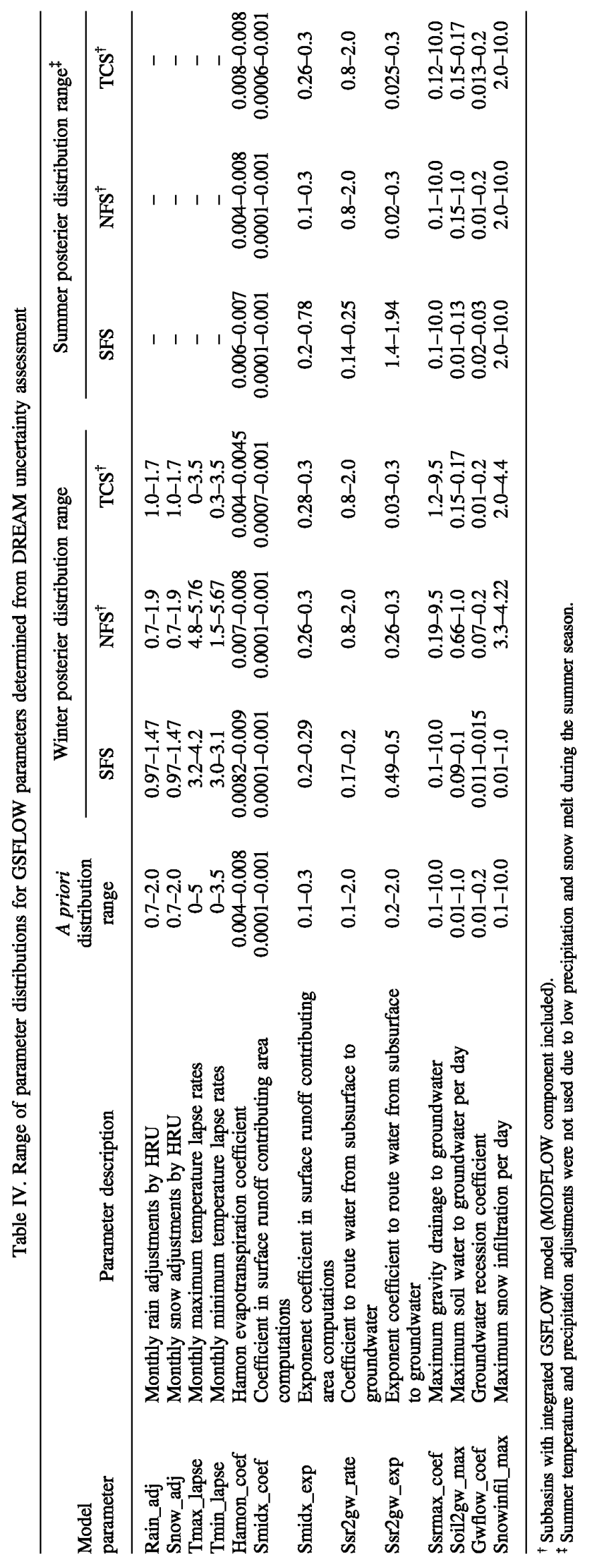



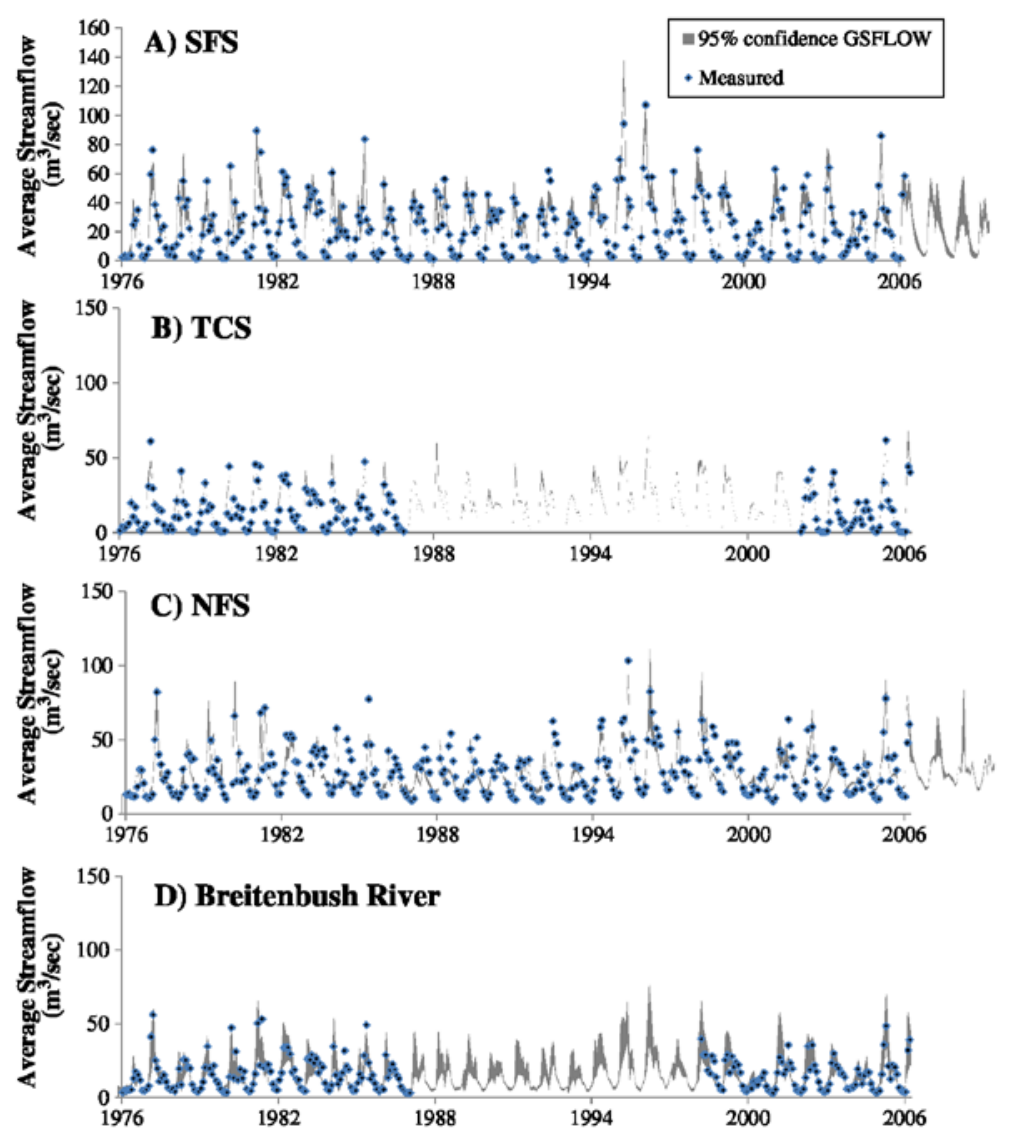

Figure 3. Average monthly streamflow compared to 95\% confidence GSFLOW output for 1976-2006 for (A) South Fork Santiam at Cascadia (SFS), (B) Thomas Creek, (C) North Fork Santiam River at Boulder Creek (NFS), and (D) Breitenbush River. Streamflow was not available for Thomas Creek or the Breitenbush River for water years 1988-2002. Breitenbush River was a subbasin with parameter distributions transferred from NFS to represent an 'ungauged basin'

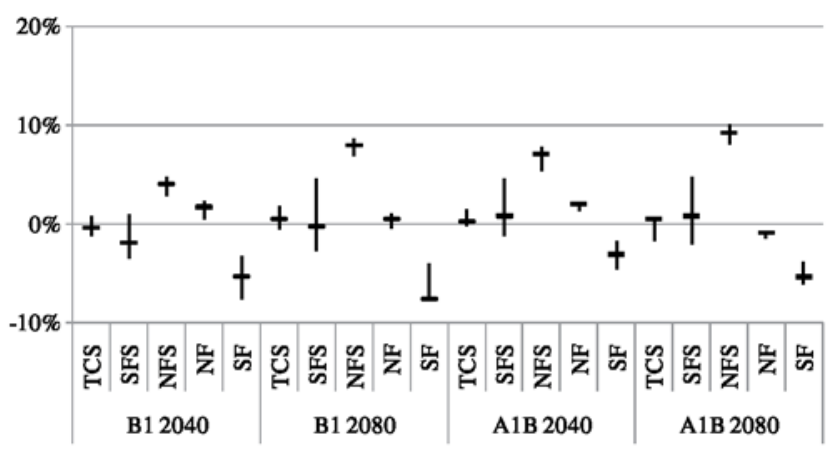

Figure 4. Range of percent change in mean annual runoff for three study subbasins (TCS, SFS, NFS) and the North Fork Santiam River (NF) and the South Fork Santiam River (SF) for the A1B and B1 scenarios during the 2040 and 2080 time periods. Horizontal dash indicates change of the ensemble mean of median value, and vertical lines indicate change of the ensemble mean of the 2.5 and 97.5 percentile values 

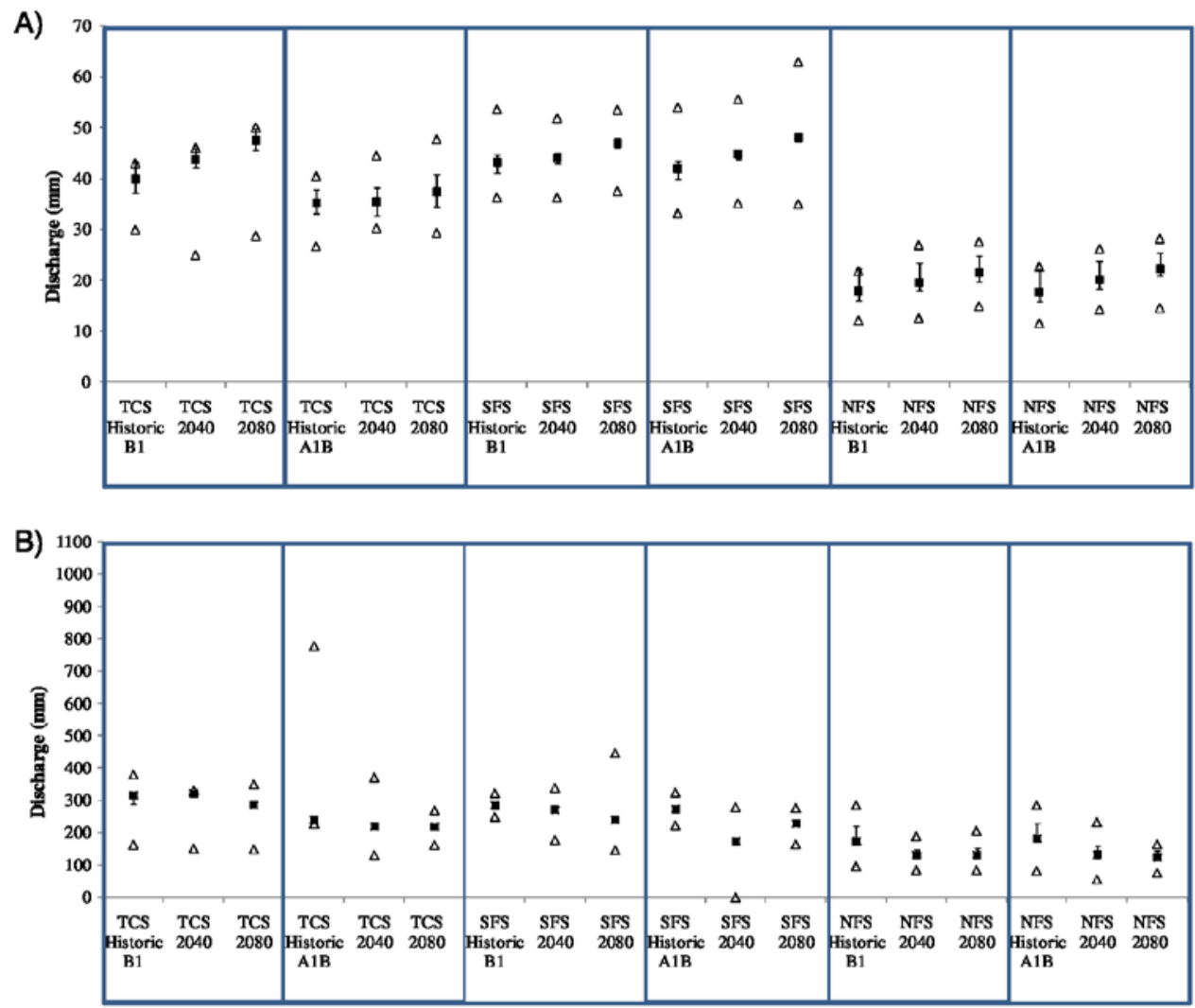

Figure 6. (A) 1-year daily peak flow and (B) 100-year daily peak flow for three study subbasins (TCS, SFS, NFS) for the historic, 2040, and 2080 time periods and greenhouse gas scenarios B1 and A1B. Ensemble means of median (box), 2.5 percentile (lower error bar), and 97.5 percentile (upper error bar); triangles represent the highest and lowest 1-year and 100-year peak flows predicted for each time period and greenhouse gas emission scenario

A) SFS

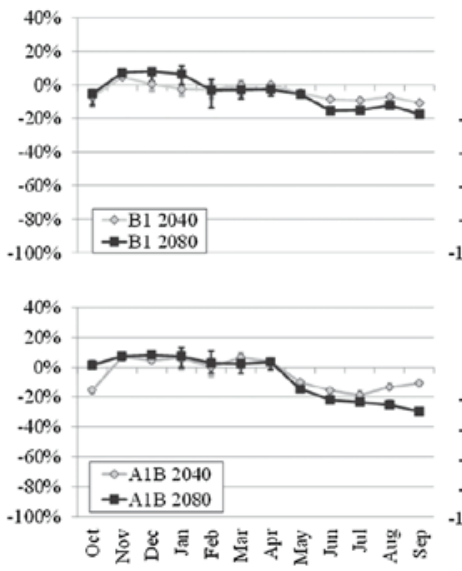

B) NFS
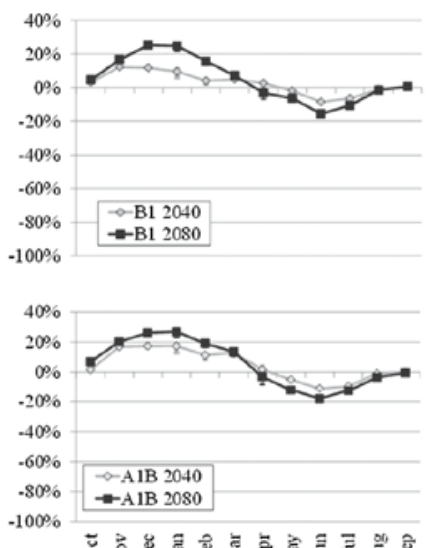

C) TCS

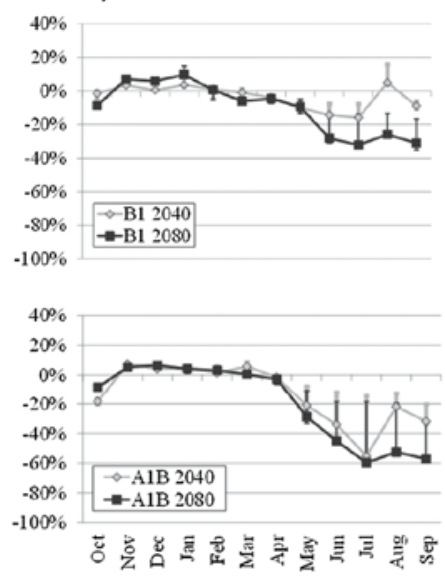

Figure 5. Percent change in monthly runoff for (A) SFS, (B) NFS, and (C) TCS for the 2040 and 2080 time periods and greenhouse gas scenarios B1 and A1B. Squares indicate the ensemble mean of the median value; error bars represent the change predicted by the ensemble mean of the 2.5 and 97.5 percentile values of the predicted runoff. Line connects the ensemble mean of the median value 

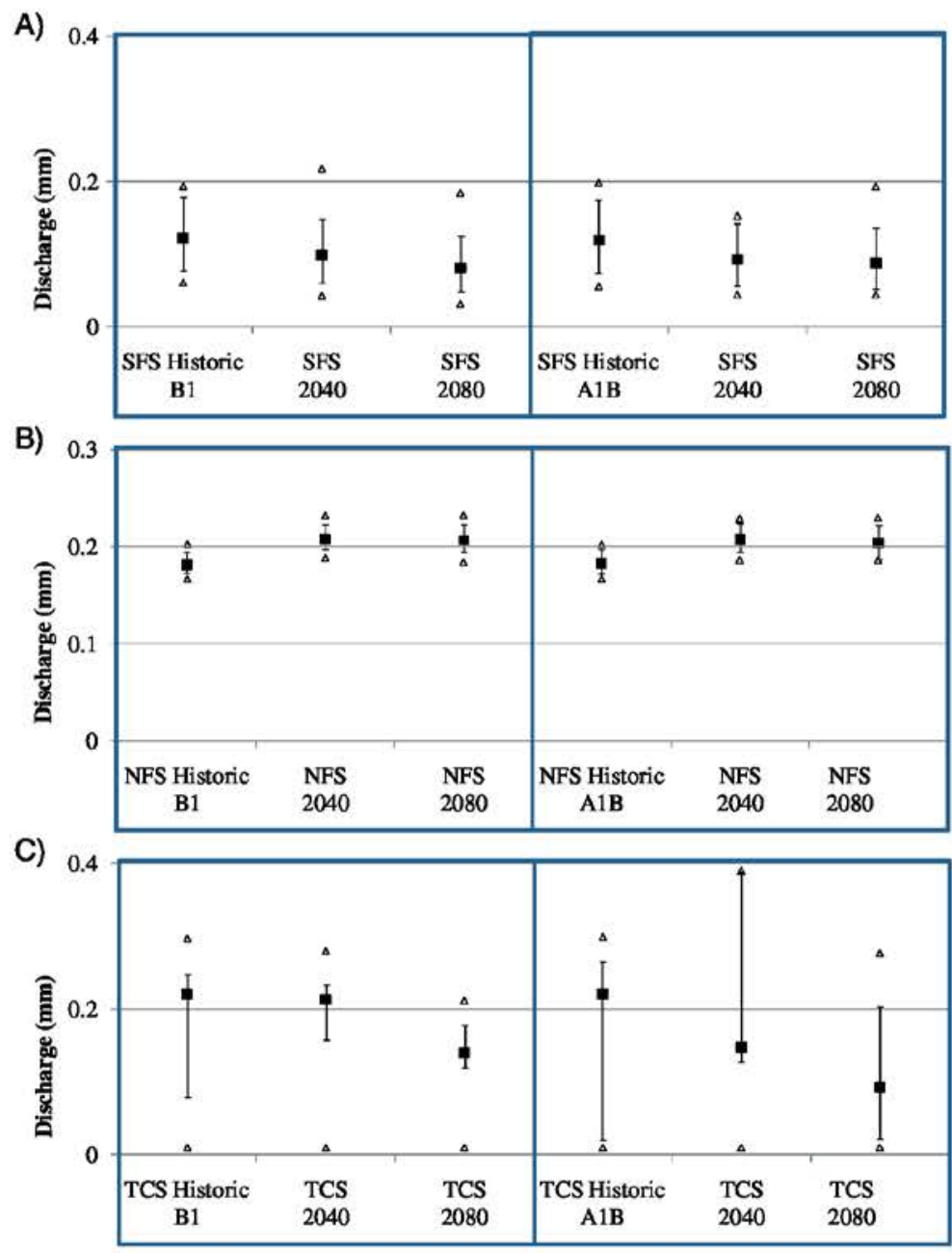

Figure 7. 10-year 7-day low flow predicted for three study subbasins: (A) SFS, (B) NFS, and (C) TCS for the historic, 2040, and 2080 time periods and greenhouse gas scenarios B1 and A1B. Ensemble means of median (box), 2.5 percentile (lower error bar), and 97.5 percentile (upper error bar); triangles represent the highest and lowest 10-year 7-day low flow peak flows predicted for each time period and greenhouse gas scenario 

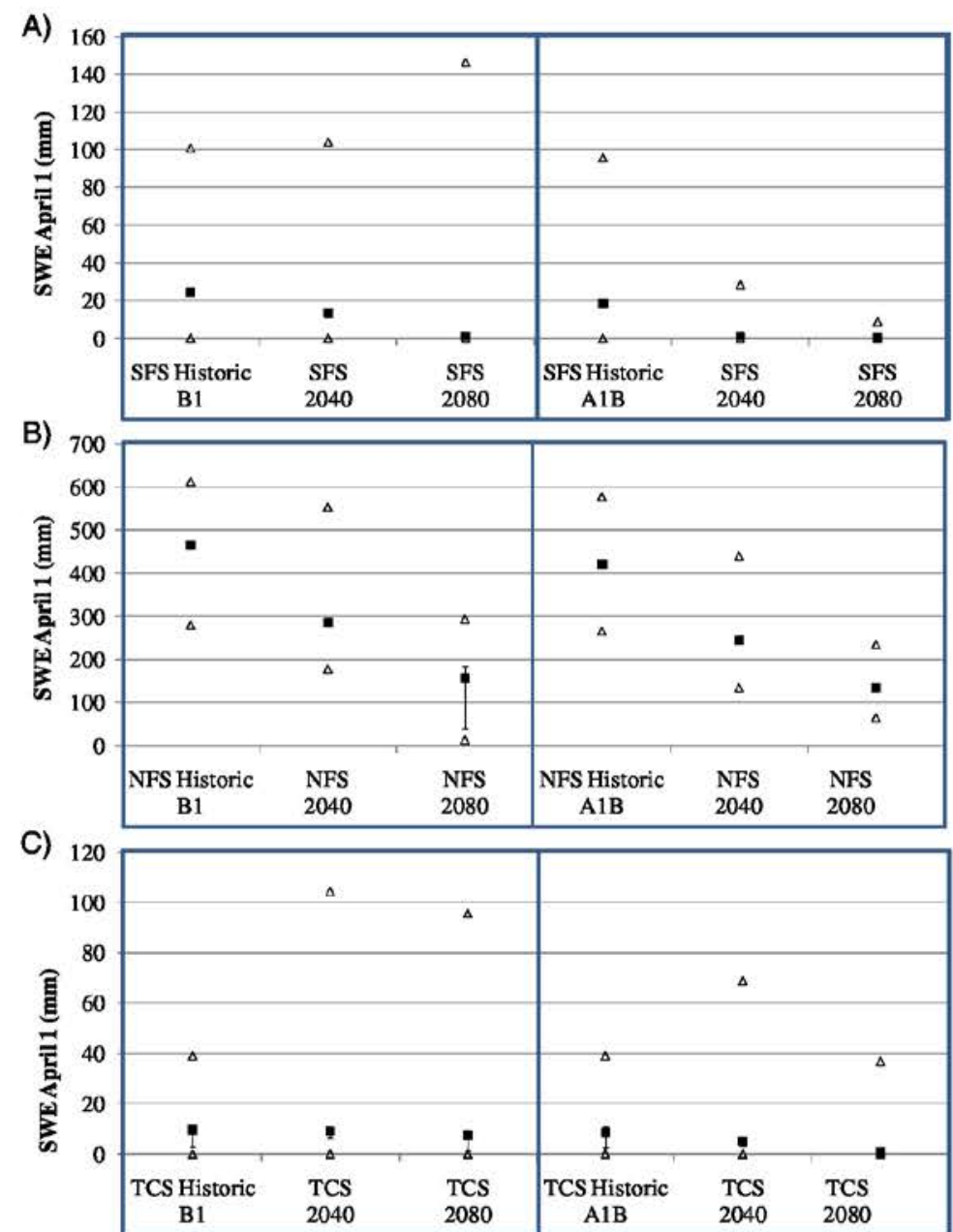

Figure 8. Snow water equivalent (SWE) (mm) on April 1 for the three study subbasins for the historic, 2040, and 2080 time periods and greenhouse gas scenarios B1 and A1B: (A) SFS, (B) NFS, and (C) TCS. Box represents ensemble mean of median SWE for each time period. Ensemble means of median (box), 2.5 percentile (lower error bar), and 97.5 percentile (upper error bar); triangles represent the highest and lowest SWE predicted for each time period and greenhouse gas scenario 


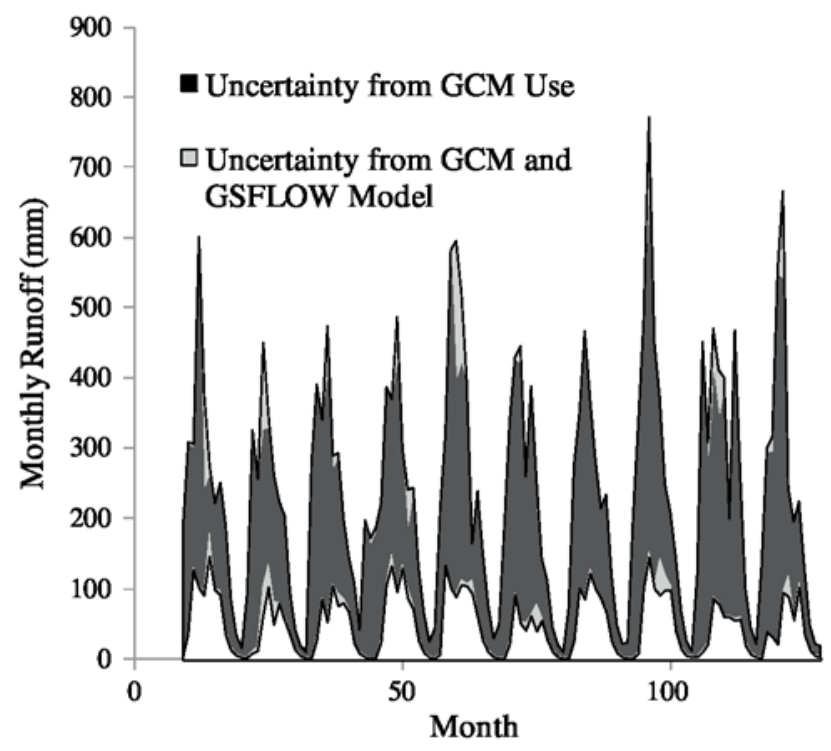

Figure 9. Comparison of range of results from uncertainty from GCM use only, using one GSFLOW model for each GCM (as represented by the median output from eight GCMs), and the uncertainty associated with using the eight GCMs and the entire range of GSFLOW output from the hydrologic model uncertainty assessment. Results are from eight GCMs of the A1B scenario for the SFS, 2001-2010 water years

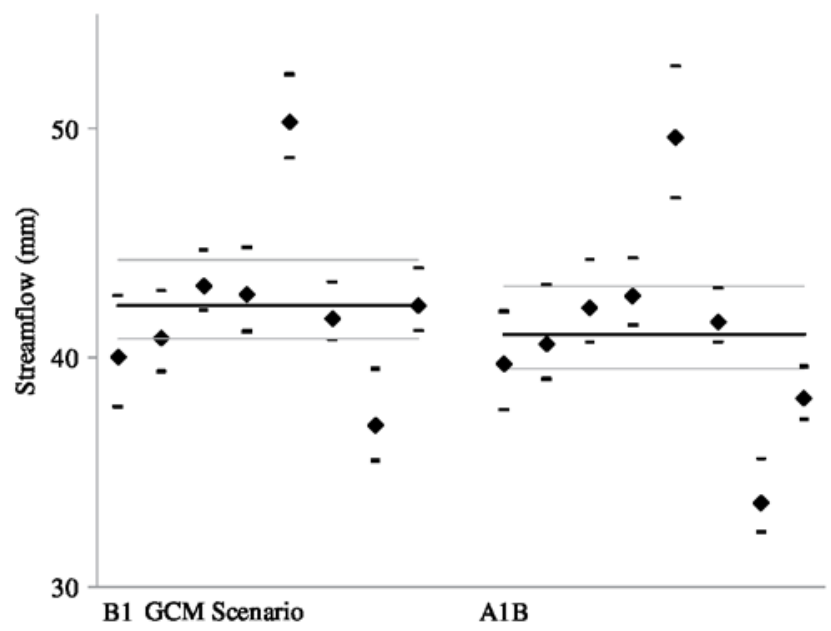

Figure 10. 1-year peak daily flow for the $2.5,50$, and 97.5 percentile time series predicted by eight GCMs for two greenhouse gas scenarios, B1 and A1B, and the ensemble mean values of the $2.5,50$, and 97.5 percentiles for each scenario for the historic time period. The 2.5 and 97.5 percentile peak flow values for each GCM are dark dashes; the 50 percentile peak flow is the diamond. The ensemble mean of the 50 percentile value is the dark line for each scenario; the ensemble means of the 2.5 and 97.5 percentile values are the light lines 